Çukurova Üniversitesi Mühendislik Mimarlık Fakültesi Dergisi, 30(2), 73-79 ss., Aralık 2015

Çukurova University Journal of the Faculty of Engineering and Architecture, 30(2), pp. 73-79, December 2015

\title{
Düzlem Çelik Çerçeve Sistemlerin Operasyonel Modal Analizi
}

\author{
M. Aydın KÖMÜR ${ }^{* 1}$, İbrahim Ö. DENEME ${ }^{1}$, Hüseyin R. YERL $\dot{I}^{2}$ \\ ${ }^{1}$ Aksaray Üniversitesi, Mühendislik-Mimarlık Fakültesi, İnşaat Mühendisliği Bölümü, Aksaray \\ ${ }^{2}$ Çukurova Üniversitesi, Mühendislik-Mimarlık Fakültesi, İnşaat Mühendisliği Bölümü, Adana
}

Geliş tarihi:04.09.2015

Kabul tarihi:19.11.2015

\section{Özet}

$\mathrm{Bu}$ çalı̧̧mada tek katlı-tek açıklıklı ve üç katlı-tek açıklıklı olmak üzere laboratuarda inşa edilmiş küçük ölçekli çelik çerçevelerin dinamik karakteristikleri nümerik ve operasyonel modal analiz yöntemleri ile belirlenmiştir. Çalışmada ilk olarak çerçeve sistemlerin Sap2000 programında sonlu eleman modelleri oluşturulmuş ve dinamik karakteristikler nümerik olarak elde edilmiştir. Daha sonra sözkonusu çerçeve sistemlerin dinamik karakteristikleri operasyonel modal analiz yöntemi ile belirlenmiştir. Her iki analizden elde edilen sonuçlar karşılaştıııldığında ivmeölçer ağırlıklarının dikkate alınmaması durumunda deneysel ve nümerik olarak elde edilen frekans değerleri arasında önemli farklar oluşmuştur. Fakat sonlu eleman modellemesinde ivme ağırlıkları dikkate alınarak analiz yapıldığında her iki yöntemden elde edilen doğal frekans sonuçların birbiri ile uyumlu olduğu görülmüştür.

Anahtar kelimeler: Operasyonel modal analiz, Çelik çerçeve, Sonlu elemanlar yöntemi

\section{Operational Modal Analysis of Plane Steel Frame Systems}

\begin{abstract}
In this study, the dynamic characteristics of small-scale steel frames of one storey-one bay and three storey-one bay, which were built in the laboratory, were determined by numerical and operational model analysis methods. As a first step, finite element models of the frame system were built by using Sap2000 program, and dynamic characteristics of this system were obtained numerically. Then, the dynamic characteristics of mentioned frame system, is determined by operational modal analysis method. Comparison the results of both analyzes, significant differences between the frequency values, could be obtained in experimentally and numerically form, if ignored weight of the accelerometer. However, carrying out the analysis of finite element modeling considering the weight of acceleration, the natural frequency of the results obtained from both methods were found to be compatible with each other.
\end{abstract}

Keywords: Operational modal analysis, Steel frame, Finite element method

\footnotetext{
"Yazışmaların yapılacağı yazar: M. Aydın KÖMÜR Aksaray Üniversitesi, İnşaat Mühendisliği Bölümü, Aksaray,makomur@gmail.com
} 


\section{GíRiș}

Operasyonel modal analiz yöntemi yapıların doğal frekans, mod şekli ve sönüm gibi dinamik karakteristiklerinin belirlenmesinde kullanılan yöntemlerden biridir. Yöntem girdi olarak trafik, dalga, rüzgar ve sismik etki gibi çevresel etkileri kullanmaktadır. Gerçek servis şartları altında dinamik karakteristiklerin belirlenmesine imkan vermesi, ölçüm esnasında yapının kullanımını kesintiye uğratmaması, hılı ve ucuz olması gibi avantajlarından dolayı tercih edilmektedir [1].

Operasyonel modal analiz 1990'ların başından beri inşaat mühendisliği alanında ilgi gören bir yöntem olup binalara, kulelere, köprülere ve deniz aşırı platformlara uygulanmıştır [2]. Sözkonusu yöntemin gerçek ölçekli yapılar yanında laboratuarda inşa edilmiş küçük ölçekli çelik yapılara uygulandığı pek çok çalışma vardır [3-10]. Bu çalışmalarda iki ya da üç boyutlu çelik yap1 modellerin ölçümleri yapılmış olup elde edilen sonuçlar teorik sonuçlarla karşılaştırılmıştır.

$\mathrm{Bu}$ çalışmada iki farklı çelik çerçeve modelinin dinamik karakteristiklerinin deneysel ve teorik olarak belirlenmesi amaçlanmıştır. Deneysel çalışmada frekans alanında ayrıştırma yönteminden yararlanılmış olup elde edilen sonuçlar teorik sonuçlar ile kıyaslanmıştır.

\section{FREKANS ALANINDA AYRIŞTIRMA YÖNTEMI}

Operasyonel modal analiz yöntemleri zaman alanında ve frekans alanında çalışan yöntemler diye kategorize edilebilir. Frekans alanında ayrıştırma (FFD) tekniği frekans alanında çalışan bir tekniktir. Bu yöntemde tepkinin güç yoğunluğu fonksiyonu (PSD) hesaplanır ve sistemin ölçeksiz mod şekillerini de içeren modal parametrelerini belirlemek için tekil değer ayrışımı gerçekleştirilir. Bilinmeyen etki ve ölçülen tepkiler arasındaki ilişki aşağıdaki gibi verilir $[11,12]$.

$\left[G_{y y}(j \omega)\right]=[\bar{H}(j \omega)]\left[G_{x x}(j \omega)\right][H(j \omega)]^{T}$
Burada $G_{x x}(j \omega)$ etkinin güç spektral yoğunluk fonksiyonunu, $\mathrm{G}_{\mathrm{yy}}(\mathrm{j} \omega)$ tepkinin güç spektral yoğunluk fonksiyonunu ve $\mathrm{H}(\mathrm{j} \omega)$ frekans davranış fonksiyonunu göstermektedir. Ayrıca " $T$ " üst indisi matrisin transpozunu, “一" üst indisi ise matrisin komplex eşleniğini göstermektedir. $\mathrm{Bu}$ bağıntıda etkinin beyaz gürültü olduğu varsayılarak etki sinyaline ait spektral yoğunluk fonksiyonu sabit alınmıştır. Tepki sinyaline ait güç spektral yoğunluk fonksiyonu, tekil değer ayrışımı gerçekleştirilerek ayrık değerler olarak,

$$
\mathrm{G}_{\mathrm{yy}}\left(\mathrm{j} \omega_{\mathrm{i}}\right)=\mathrm{U}_{\mathrm{i}} \mathrm{S}_{\mathrm{i}} \mathrm{U}_{\mathrm{i}}^{\mathrm{H}}
$$

şeklinde verilmektedir. Burada; $U_{i}, \quad u_{i j}$ tekil vektörlerinden (mod vektörlerinden) oluşan birim matrisi, $\mathrm{S}_{\mathrm{i}}, \mathrm{s}_{\mathrm{ij}}$ tekil değerlerden (özdeğerlerden) oluşan diyagonal matrisi göstermektedir $[12,13]$.

\section{3. ÇERÇEVE SİSTEMLERİN TANIMLANMASI}

Bu çalışmada laboratuvarda üretilen iki farklı çelik yapı dikkate alınmıştır (Şekil 1, 2). Modellerden biri tek katlı- tek açıklıklı çerçeve diğeri ise üç katlı-tek açıklıklı çerçevedir. Tek katlı - tek açıklıklı çerçeve sistemin açıklığg $60 \mathrm{~cm}$ yüksekliği ise $120 \mathrm{~cm}$ olarak modellenmiştir. Kolon ve kirişler aynı profilden üretilmiş olup kesit boyutları $7 \times 1 \mathrm{~cm}$ dır. Çerçeve sistemin kolon kiriş birleşimi kaynakla gerçekleştirilmiş olup mesnetleri ankastredir. Üç katlı-tek açıklıklı çerçeve sistem daha önce literatürde [14] çalışılmış bir modelle aynı ölçülere sahip olup kat yüksekliği ve açıklığı $40 \mathrm{~cm}$ dir. Aynı profilden üretilmiş olan kolon ve kirişlerin kesit boyutları $3 \times 1 \mathrm{~cm}$ dir. Sözkonusu çerçeve sistemin kolon kiriş bağlantı yerleri kaynaklı olup mesnetleri ankastredir.

\section{MODAL PARAMETRELERIN BELİRLENMESİ}

Çalışmaya konu olan iki farklı çelik modelin dinamik karakteristiklerinin belirlenmesinde bir nümerik yöntem olan sonlu elemanlar yöntemi ile operasyonel modal analiz yönteminden yararlanılmıştır. 


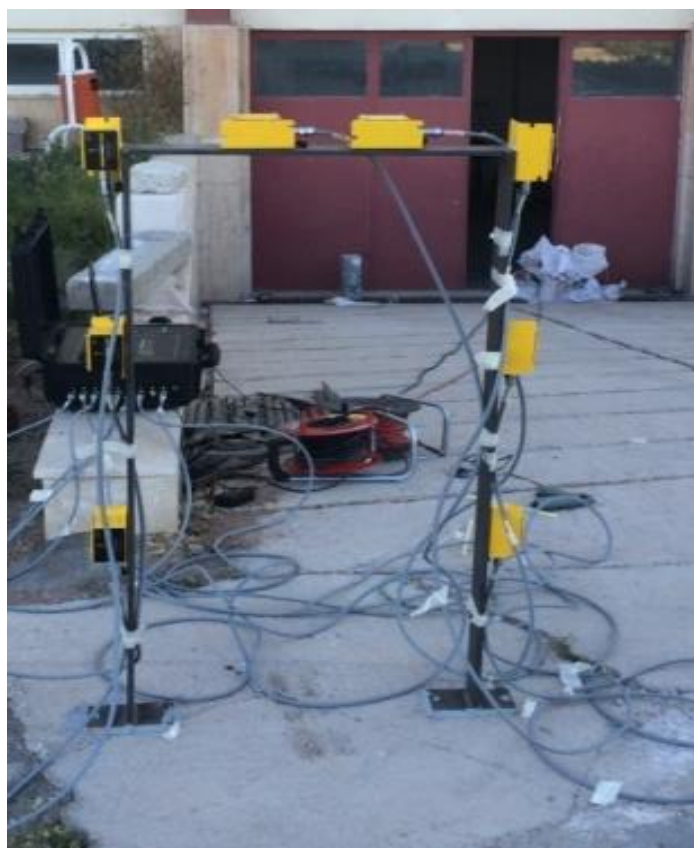

Şekil 1. Tek katlı-tek açıklıklı çerçeve sistem ve ivmeölçer yerleşimi

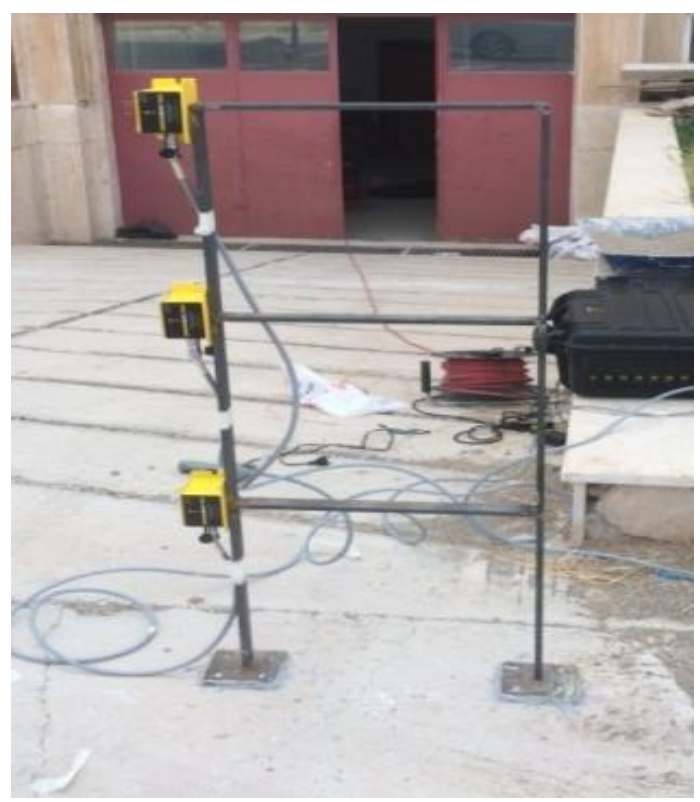

Şekil 2. Üç katlı-tek açıklıklı çerçeve sistem ve ivmeölçer yerleşimi

\section{1. Çerçeve Sistemlerin Sonlu Eleman Analizi}

Yapıların sonlu eleman modelinin oluşturulması sap2000 paket programında [15] yapılmıştır.

Modellemede malzeme özelliği olarak elastisite modülü $\mathrm{E}=2.062 \times 10^{5} \mathrm{MPa}$, posisson oranı $\mathrm{v}=0.3$ ve kütle yoğunluğu $7850 \mathrm{~kg} / \mathrm{m}^{3}$ kullanılmıştır. Söz konusu yapıların mesnetleri ankastre, düğüm noktaları ise rijit olarak dikkate alınmıştır.

\subsubsection{Tek Katı-Iek Açıklıkıı Çerçeve Sistem}

Modellemede kolon ve kirişler sekizer elemana bölünmüştür. Analiz sonucunda 6 moda ait doğal frekans değerleri ve mod şekilleri Şekil 3'te verilmiştir.
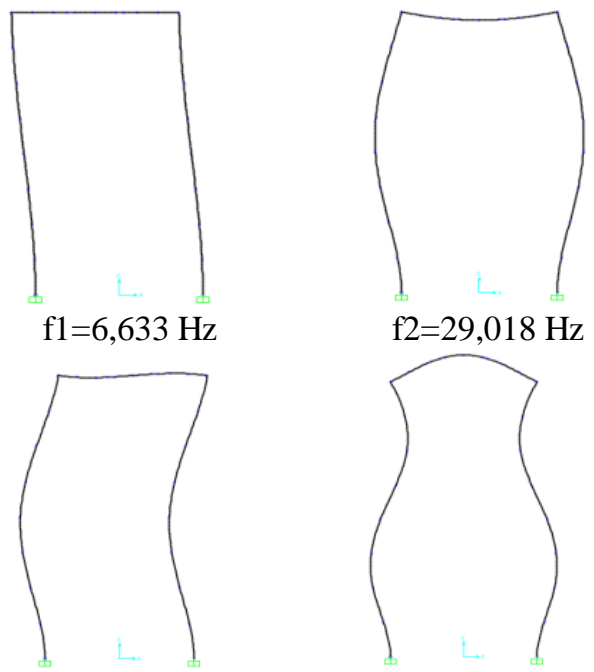

$\mathrm{f} 3=38,70 \mathrm{~Hz}$
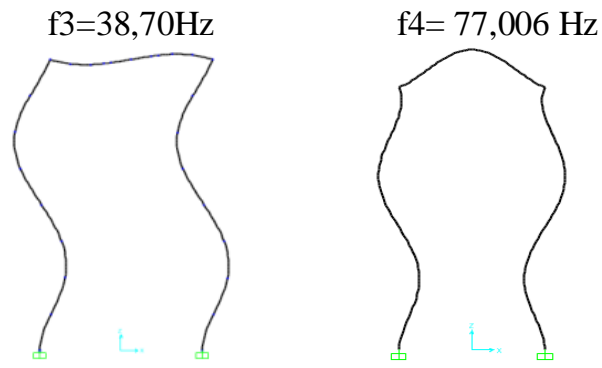

$\mathrm{f} 5=98,130 \mathrm{~Hz}$

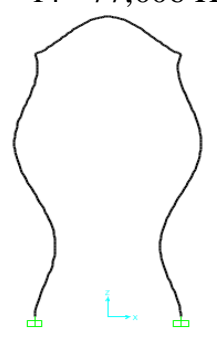

$\mathrm{f} 6=114,84 \mathrm{~Hz}$

Şekil 3. Sonlu eleman analizinden elde edilen mod şekilleri ve doğal frekans değerleri 


\subsection{2. Üç Katı-Tek Açıklıkı Çerçeve Sistem}

Modellemede kolon ve kirișler 6 şar elemana bölünmüştür. Analiz sonucunda 3 moda ait doğal frekans değerleri ve mod şekilleri Şekil 4'de verilmiştir.

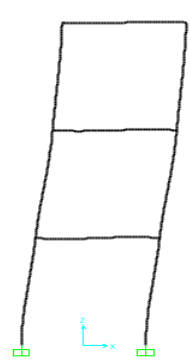

$\mathrm{f} 1=13,972$

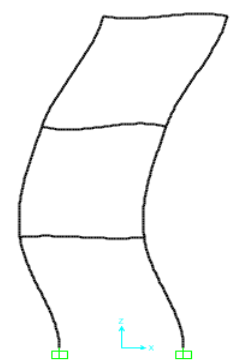

$\mathrm{f} 2=46,157$

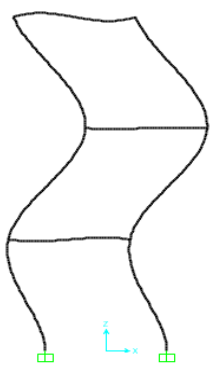

$\mathrm{f} 3=83,173$
Şekil 4. Sonlu eleman analizinden elde edilen mod şekilleri ve doğal frekans değerleri

\subsection{Operasyonel Modal Analiz}

Çerçeve sistemlerin dinamik karakteristiklerinin titreşim testleri yapılarak belirlenmesinde Operasyonal Modal Analiz yöntemi kullanılmıştır. Ölçümler tek eksenli ivmeölçerler kullanılarak $0-250 \mathrm{~Hz}$ frekans aralığında gerçekleştirilmiştir. İvmeölçerlerden elde edilen sinyaller ölçüm süresince (15 dakika) 20 kanallı TESTBOX6501 veri toplama ünitesinde birleștirilip TESTLAB NETWORK yazılımına aktarılmıştır. Burada sinyaller işlendikten sonra Artemis yazılımında [16] frekans alanında ayrıştırma yöntemi kullanılarak dinamik karakteristikler elde edilmiştir.

\subsubsection{Tek Açıkıklı Tek Katı Çerçeve Sistem}

Çerçeve sistemin ölçülmesinde 8 adet ivmeölçer kullanılmıştır. İvmeölçerlerden 6 tanesi yatay doğrultuda ölçüm yapacak şekilde kolonlara, iki tanesi ise düşey doğrultu ölçüm yapacak şekilde kirişe yerleştirilmiştir. Çerçeve sistem için modal parametreler ölçülen her bir titreşim sinyalinden tekil değerler olarak elde edilmiş ve Şekil 5'de gösterilmiştir.

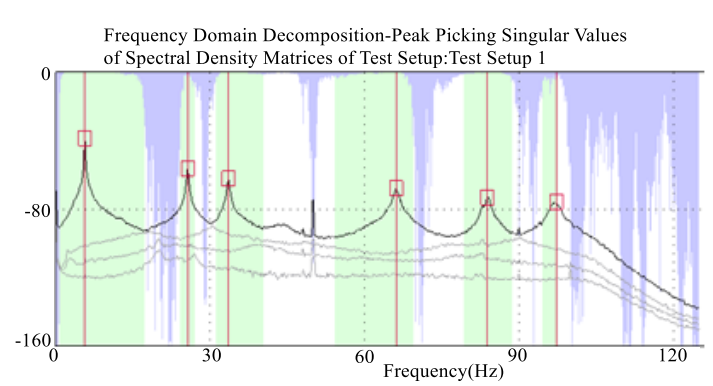

Şekil 5. Çerçeve sistemde her bir titreşim sinyaline ait tekil değerler

Çelik yapılar üzerinde yapılan ölçümler sonucunda elde edilen verilerden sağlanan mod şekilleri ise Şekil 6'da verilmiştir.

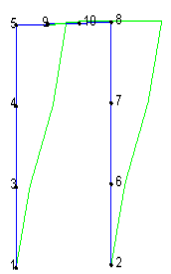

$\mathrm{f} 1=5,615$

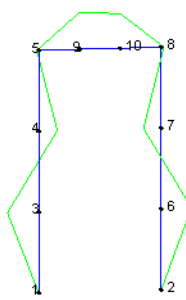

$f 4=66,16$

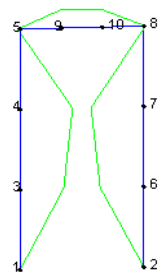

$\mathrm{f} 2=25,63$

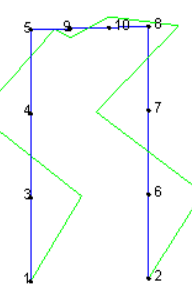

$\mathrm{f} 5=83,86$

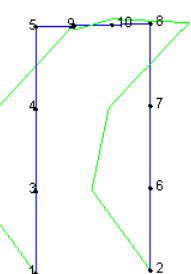

$\mathrm{f} 3=33,57$

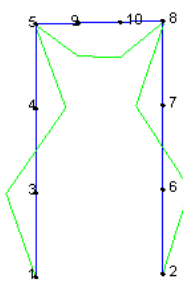

$f 6=97,29$
Şekil 6. Tek katlı çerçeve sisteme ait mod şekilleri ve doğal frekans değerleri

\subsection{2. Üç Katlı-Tek Açıklıklı Çerçeve Sistem}

Çerçeve sistemin ölçülmesinde 8 ivmeölçer kullanılmıştır. İvmeölçerlerden 6 tanesi yatay doğrultuda ölçüm yapacak şekilde kolonlara iki tanesi ise düşey doğrultu ölçüm yapacak şekilde kirişe yerleştirilmiştir. Çerçeve sistem için modal parametreler ölçülen her bir titreşim sinyalinden 
tekil değerler olarak elde edilmiş ve Şekil 7'de gösterilmiştir.

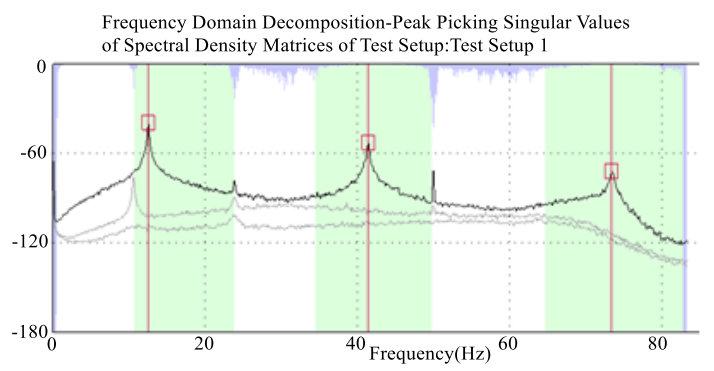

Şekil 7. Çerçeve sistemde her bir titreşim sinyaline ait tekil değerler

Çelik yapılar üzerinde yapılan ölçümler sonucunda elde edilen verilerden sağlanan mod şekilleri ise Şekil 8'de verilmiştir.

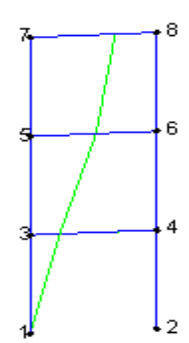

$\mathrm{f} 1=12,53$

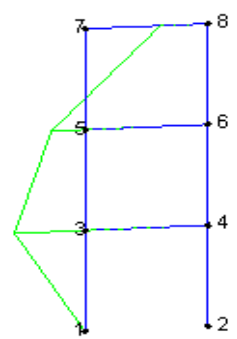

$\mathrm{f} 2=41,42$

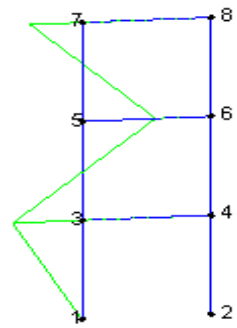

$\mathrm{f} 3=73,4$
Şekil 8. Üç katlı çerçeve sisteme ait mod şekilleri ve doğal frekans değerleri

\section{NÜMERIK VE DENEYSEL SONUÇLARIN DEĞERLENDİRILMESİ}

Tek katlı-tek açıklıklı çelik çerçeve sistem için sonlu elemanlar modellemesinden ve Frekans alanında ayrıștırma yönteminden elde edilen frekans değerleri Çizelge 1'de verilmiştir. Her iki yöntemin frekans sonuçları kıyaslandığında minimum hata $\% 13,22$ ile ikinci modda, maksimum hata ise $\% 18,13$ ile birinci modda meydana gelmiștir. $\mathrm{Bu}$ hatalar ivmeölçerlerin ağırlığının ölçülen modellerin ağırlığı yanında ihmal edilemeyecek düzeyde olmasından kaynaklanmaktadır. Sonlu eleman modellemesi ivmelerin kütlelerini de dikkate alacak şekilde güncellendiğinde her iki analizden elde edilen sonuçların birbirine çok yaklaştığı görülmektedir. İlk altı mod için minimum hata \%0,36 olarak 5 . modda, maksimum hata ise $\% 1,61$ ile 2 . modda gerçekleşmiştir.

Benzer şeklide üç katlı-tek açıklıklı çerçeve sistemin sonlu elemanlar modellemesinden ve frekans alanında ayrıştırma yönteminden elde edilen frekans değerleri Çizelge 2'de verilmiştir. Her iki yöntemden sağlanan frekans değerleri kıyaslandığında hatalar \% 11,43-13,31 arasında değişmektedir. İvme ağırlıkları da dikkate alınarak yapılan sonlu elemanlar modellemesinden sonra sonuçların birbirine yaklaştığı görülmüştür. İlk üç mod için maksimum hata $\% 0,40$ olarak gerçekleşmiştir.

Ayrıca sözkonusu çerçeve sistemle ile ilgili olarak literatürde mevcut olan frekans değerleri de Çizelge 2'de verilmiştir. Bu sonuçlar nümerik sonuçlara çok yakındır. Bunun sebebi ölçümde tek ivmeölçerin kullanılması ve kullanılan ivmeölçer ağırlığının daha düşük olmasıdır.

Çizelge 1. Tek katlı çerçeve sisteme ait nümerik ve deneysel doğal frekans değerleri

\begin{tabular}{|c|c|c|c|c|c|}
\hline \multirow{2}{*}{ Mod } & \multicolumn{5}{|c|}{ Tek katl1- tek aç1klıklı çerçeve } \\
\cline { 2 - 6 } & FFD & SEY & $\begin{array}{c}\text { Hatal } \\
(\%)\end{array}$ & $\begin{array}{c}\text { Güncel } \\
\text { SEY }\end{array}$ & $\begin{array}{c}\text { Hata } \\
(\%)\end{array}$ \\
\hline 1 & 5,615 & 6,633 & 18,13 & 5,637 & 0,39 \\
\hline 2 & 25,63 & 29,018 & 13,22 & 25,218 & 1,61 \\
\hline 3 & 33,57 & 38,700 & 15,28 & 33,289 & 0,84 \\
\hline 4 & 66,16 & 77,006 & 16,39 & 65,618 & 0,82 \\
\hline 5 & 83,86 & 98,130 & 17,02 & 84,161 & 0,36 \\
\hline 6 & 97,29 & 114,84 & 18,04 & 96,809 & 0,49 \\
\hline
\end{tabular}


Çizelge 2. Üç katlı çerçeve sisteme ait nümerik ve deneysel doğal frekans değerleri

\begin{tabular}{|c|c|c|c|c|c|}
\hline \multicolumn{7}{|c|}{ Tek katl1- tek açıklıklı çerceve } \\
\hline FFD & SEY & Literatür & $\begin{array}{c}\mid \text { Hata } \\
(\%)\end{array}$ & $\begin{array}{c}\text { Güncel } \\
\text { SEY }\end{array}$ & $\begin{array}{c}\mid \text { Hata| } \\
(\%)\end{array}$ \\
\hline 12,53 & 13,971 & 14 & 11,50 & 12,58 & 0,40 \\
\hline 41,42 & 46,155 & 46,50 & 11,43 & 41,26 & 0,39 \\
\hline 73,4 & 83,167 & 85 & 13,31 & 73,68 & 0,38 \\
\hline
\end{tabular}

\section{SONUÇLAR}

$\mathrm{Bu}$ çalışmada iki farklı düzlem çerçeve sistemin mod şekilleri ve doğal frekansları nümerik ve deneysel yöntemlerle belirlenmiştir. Her iki çelik çerçeve sistemde de operasyonel modal analizden elde edilen doğal frekans değerleri ile sonlu eleman modellemesinden elde edilen sonuçlar arasında önemli farklar oluşmuştur. İvmeölçer ağırlıklarının sonlu eleman modellemesinde dikkate alınması durumunda birbiri ile uyumlu sonuçlar elde edilmiştir.

Her iki çerçeve sistem için nümerik ve operasyonel modal analizden elde edilen mod şekillerinin birbiri ile uyumlu olduğu görülmüştür. İvmeölçer ağırlıklarının çerçeve sistemlerin doğal frekanslarına etkisini azaltmak için ağırlığı daha küçük olan ivmeölçerler tercih edilmelidir.

\section{KAYNAKLAR}

1. Rainieri, C., Fabbrocino, G., 2011. Operational Modal Analysis for the Characterization of Heritage Structures, GEOFIZIKA, 28, pp.109126.

2. Zhang, L., Brincker, R., Andersen, P. 2005. An Overview of Operational Modal Analysis:Major Development and Issues, Proc. Of the International Modal Analysis Conference, Copenhangen, Denmark, 26-27, April.

3. Molina, F.J., Pascual, R., Golinval, J.C., 2003. Descriptionof the Steelquake Benchmark, Mechanical Systems and Signal Processing, 17(1),pp. 77-82.
4. Xiaodon, J., Jiaru, Q., Longhe, X., 2007. Damage Diagnosis of a Two-storey Spatial Steel Braced-frame Model, Structural Control and Health Monitoring, 14, pp.1083-1100.

5. Türker, T., Kartal, M.E., Bayraktar, A., Muvafik, M., 2009. Assessment of Semi-rigid Connections in Steel Structures by Modal Testing, Journal of Constructional Steel Research, 65, pp.1538-1547.

6. Türker, T., Bayraktar, A., 2011. Experimental and Numerical Investigation of Brace Configuration Effects on Steel Structures, Journal of Constructional Steel Research,Cilt 67, 854-65.

7. Davoodi, M.R., Mahdavi, M., Mostafavian, S.A., 2012. Experimental and Analytical Determination of Dynamic Properties of a Steel Frame with Bolted Flange Joints, Proceedings of International Conference on Engineering and Information Technology "ICEIT2012", Toronto, Canada, Sep. 17-18.

8. Gomaa, F., Tayel, M., Kandil, K., Hekal, G., 2012. Validation Study Illustrates the Accuracy of Operational Modal Analysis Identification", International Journal of Emerging Technology and Advanced Engineering, ISSN 2250-2459, 2(11), 658-667.

9. Türker, T., Bayraktar, A., 2013. Finite Element Model Calibration of Steel Frame Buildings with and without Brace, Journal of Constructional Steel Research, 90, pp. 164173.

10. Dönmez, C., Karakan, E., 2009. Köprülerde Deneysel Modal Analiz Uygulamaları, İMO Teknik Dergi, 4851-4863, Yazı 318.

11. Bendat, J.S., Piersol, A.G., 1986. Random Data: Analysis and Measurement Procedures, John Wiley \& Sons, USA.

12. Brincker, R., Zhang, L., Andersen, P., 2000. Output-only Modal Analysis by Frequency Domain Decomposition. in: Proceedings of the ISMA25 Noise and Vibration Engineering, Leuven, Belgium.

13. Bayraktar, A., Türker, T., Altunışık, A.C., Sevim, B., Şahin, A., Özcan D.M., 2010. Binaların Dinamik Parametrelerinin Operasyonal Modal Analiz Yöntemiyle Belirlenmesi İMO Teknik Dergi, Yazı 337, 5185-5205. 
14. Türker, T., 2005. Çelik Çerçeve Sistemlerin Dinamik Karakteristiklerinin Deneysel Modal Analiz Yöntemiyle Belirlenmesi, Yüksek Lisans Tezi, KTÜ Fen Bilimleri Enstitüsü, Trabzon.

15. CSI, SAP2000 V-14, 2009. Integrated Finite Element Analysis and Design of Structures Basic Analysis Reference Manual, Computers and Structures, Inc., Berkeley, CA, USA.

16. ARTeMIS V-5.3,Ambient Response Testing and Modal Identification Software, Structural Vibration Solutions A/S, Denmark, www.svibs.com. 
